\title{
Design, Development and Experimental Investigation on Various Biogas Upgrading Techniques
}

\author{
H. S. Salave ${ }^{1,2}$, A. D. Desai ${ }^{3}$ \\ ${ }^{1}$ (Department of Mechanical Engineering, M.E.S College of Engineering, SPPU Pune) \\ ${ }^{2}$ (Research Scholar Dr. D. Y. Patil Institute of Engineering and Technology, Pimpri, SPPU Pune) \\ ${ }^{3}$ (Department of Mechanical Engineering, Shree Ramchandra College of Engineering Wagholi, SPPU, Pune)
}

\begin{abstract}
Biogas upgrading and the production of bio-methane nowadays is a state-of-the-art-process of gas separation. A number of different technologies to fulfil the task of producing a bio-methane stream of sufficient quality to act as a vehicle fuel or to be injected into the natural gas grid are already commercially available and have proven to be technically and economically feasible. Nevertheless, intensive research is still in progress to optimise and further develop these technologies as well as to apply novel technologies to the field of biogas upgrading. All technologies have their own specific advantages and disadvantages and this review shows, that no technology is the optimal solution to each and every biogas upgrading situation. The right choice of the economically optimal technology is strongly depending on the quality and quantity of the raw biogas to be upgraded, the desired bio-methane quality and the final utilisation of this gas, the operation of the anaerobic digestion plant and the types and continuity of the used substrates as well as the local circumstances at the plant site. This choice is to be made by the planner and future operator and this report is worked out to act as a supporting guideline during the planning phase of a new bio-methane production site.
\end{abstract}

Keywords - Biogas, $\mathrm{CO}_{2}$ Sequestration, hydrogen sulphide $\left(\mathrm{H}_{2} \mathrm{~S}\right)$ biogas upgrading, bio-methane

\section{INTRODUCTION}

Biogas upgrading is a gas separation task finally ending up with a methane-rich product gas stream with a certain specification. Depending on the raw biogas composition this separation task comprises the separation of carbon dioxide (and thus increasing the heating value and Wobbe-Index), the drying of the gas, the removal of trace substances like oxygen, nitrogen, hydrogen sulphide, ammonia or siloxanes as well as the compression to a pressure needed for the further gas utilisation. Furthermore, tasks like odorisation (if injected to a local low-pressure natural gas grid) or adjustment of the heating value by propane-dosing might have to be performed. The raw biogas basically is split into two gas streams during biogas upgrading: the methane-rich bio methane stream and the carbon-dioxide-rich off gas stream. As no separation technology is perfect, this wastegas stream still contains a certain amount of methane depending on the methane recovery of the applied technology. Whether this gas stream is legally permitted to be vented to the atmosphere or has to be further treated is depending on the methane content, on the methane slip of the upgrading plant (amount of methane in the off gas related to the amount of methane in the raw biogas) and on the legal situation at the plant site. The following sections will describe the technologies available for the most important tasks in biogas upgrading (desulphurisation, removal of carbon dioxide, drying). The removal of trace components will be discussed briefly and the possibilities of off gas treatment will be presented at the end of this section. To give a short overview over the separation task and the involved gas streams a basic flow sheet of biogas is shown in fig. 1.

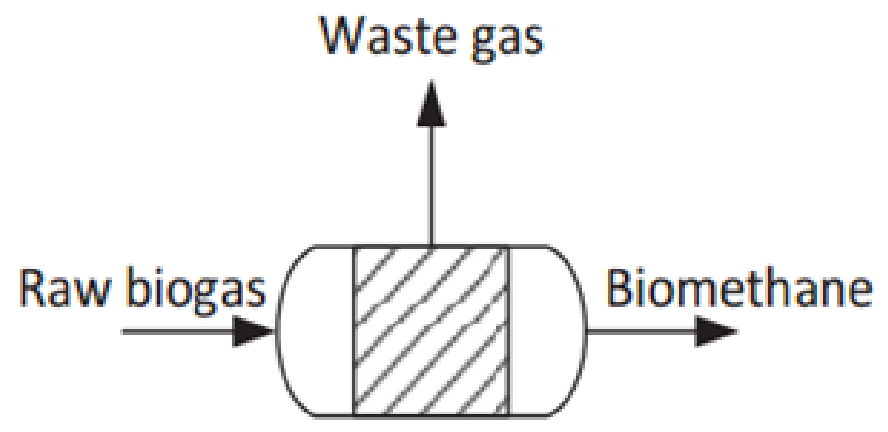

Fig.1 Basic flow sheet of biogas. 
Alternatively, the methane in the off gas can be oxidised by a low-calorific combustor or by catalytic combustion. A number of manufacturers already provide applicable technologies on a commercial basis. These systems provide stable combustion even at methane contents of as low as $3 \%$ in the combustion mixture with air. The treatment of off gas containing even less methane is increasingly difficult as not enough energy is provided during the combustion of this gas and raw biogas or bio methane have to be added in order to reach a stable oxidation. This is why it does not make sense to choose an upgrading technology with a methane recovery as high as possible because you always have to deal with the off gas. The integration of the upgrading plant into the biogas production facility and the overall concept of the bio methane production site are much more important. Only very few upgrading technologies with extremely high methane recoveries provide an off gas that is permitted to be directly vented to the atmosphere. Table- 1 shows typical gas compositions of biogas

Table-1 Compositions of biogas

\begin{tabular}{|l|l|}
\hline MATTER & Percentages (\%) \\
\hline Methane & $50-75$ \\
\hline Carbon Dioxide & $25-50$ \\
\hline Nitrogen & $0-10$ \\
\hline Hydrogen & $0-1$ \\
\hline Hydrogen Sulphide & $0-3$ \\
\hline Oxygen & $0-2$ \\
\hline
\end{tabular}

\section{II. $\mathrm{CO}_{2}$ SCRUBBING FROM BIOGAS}

A variety of processes are being used for removing $\mathrm{CO} 2$ from natural gas in petrochemical industries. Several basic mechanisms are involved to achieve selective separation of gas constituents. These may include physical or chemical absorption, adsorption on a solid surface, cryogenic separation and chemical conversion.

\section{A. Physical Absorption}

For biogas scrubbing physical/chemical absorption method is generally applied as they are effective even at low flow rates that the biogas plants are normally operating at. Also the method is less complicated, requires fewer infrastructures and is cost effective. Dubey [3] tried three water scrubbers having diameters 150 mm (height: $1.5 \mathrm{~m}), 100 \mathrm{~mm}$ (height: $10 \mathrm{~m}$ ) and $75 \mathrm{~mm}$ (height: $10 \mathrm{~m}$ ) to absorb CO2 present $(37-41 \%)$ in the biogas. He found that the $\mathrm{CO} 2$ absorption is influenced by the flow rates of gas and water than different diameters of scrubbers. The basic flow diagram of Water Scrubbing is shown in fig. 2.

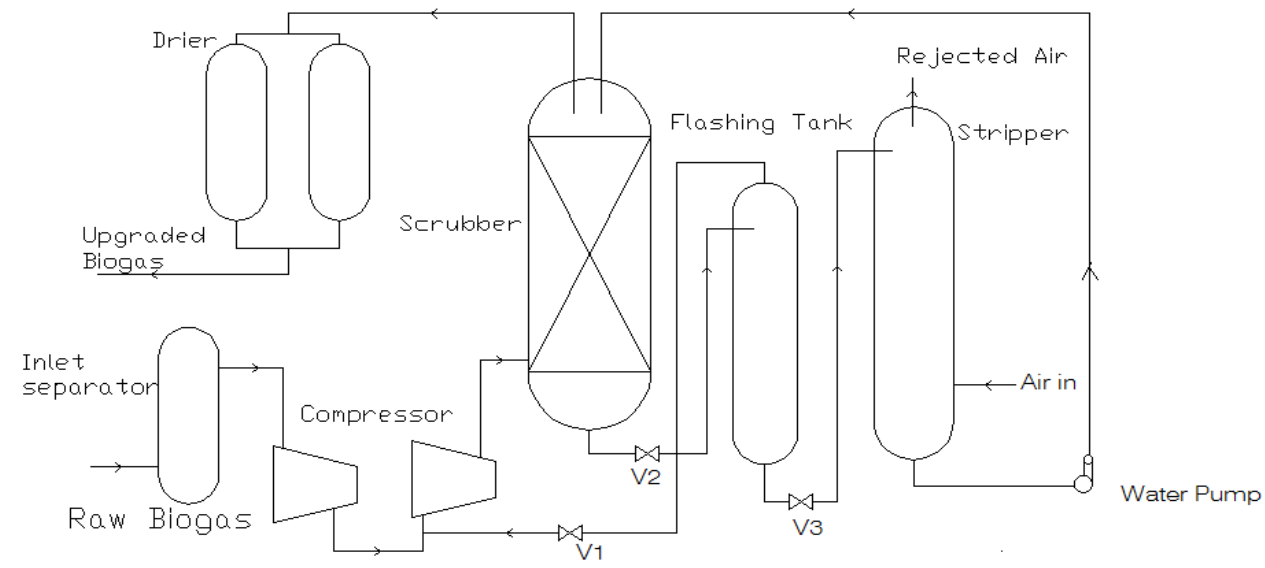

Fig. 2 Water Scrubbing

Khapre [4] designed a continuous counter-current type scrubber with gas flow rate of $1.8 \mathrm{~m} 3 / \mathrm{h}$ at 0.48 bar pressure and water inflow rate of $0.465 \mathrm{~m} 3 / \mathrm{h}$. It continuously reduced $\mathrm{CO} 2$ from $30 \%$ at inlet to $2 \%$ at outlet by volume.Bhattacharya et al. [5] developed one such water scrubbing system. The process provides $100 \%$ pure methane but is dependent on factors like dimensions of scrubbing tower, gas pressure, and composition of raw biogas, water flow rates and purity of water used.Vijay [6] developed a packed bed type scrubbing system using the locally available packing materials removing 30-40\% more $\mathrm{CO} 2$ by volume compared with the scrubbing systems without a packed bed.The G.B. Pant University of Agriculture and Technology, Pantnagar, India [7] developed a $6 \mathrm{~m}$ highs scrubbing tower, packed up to $2.5 \mathrm{~m}$ height with spherical plastic balls of $25 \mathrm{~mm}$ diameter. The raw biogas compressed at 5.88 bar pressure was passed at a flow rate of $2 \mathrm{~m} 3 / \mathrm{h}$ while water was 
circulating through the tower. A maximum of $87.6 \%$ of the $\mathrm{CO} 2$ present could be removed from the raw biogas. Water scrubbing method is popular for $\mathrm{CO} 2$ removal in sewage sludge based biogas plants in Sweden, France and USA. The results show that $5-10 \% \mathrm{CO} 2$ remains in biogas after scrubbing [8].

\section{B. Chemical Absorption}

Chemical absorption involves formation of reversible chemical bonds between the solute and the solvent. Regeneration of the solvent, therefore, involves breaking of these bonds and correspondingly, a relatively high energy input. Chemical solvents generally employ either aqueous solutions of amines, i.e. mono-, di- or tri-ethanolamine or aqueous solution of alkaline salts, i.e. sodium, potassium and calcium hydroxides. Biswas et al. [9] reported that by bubbling biogas through 10\% aqueous solution of mono-ethanolamine (MEA), the $\mathrm{CO} 2$ content of the biogas was reduced from 40 to $0.5-1.0 \%$ by volume. MEA solution can be completely regenerated by boiling for $5 \mathrm{~min}$ and thus can be used again.

\section{Adsorption on a Solid Surface}

Adsorption process involves the transfer of solute in the gas stream to the surface of a solid material, where they concentrate mainly as a result of physical or Vander wall forces. Commercial adsorbents are generally granular solids with a large surface area per unit volume. By a proper choice of adsorbent, the process can remove $\mathrm{CO} 2, \mathrm{H} 2 \mathrm{~S}$, moisture and other impurities either selectively or simultaneously from biogas. Schomaker et al. [10] reported that $\mathrm{CO} 2$ could be removed from biogas by pressure swing adsorption which consists of at least three active carbon beds. One of the beds is fed with biogas under pressure (6 bars) $\mathrm{CO} 2$ is adsorbed. When there is saturation of $\mathrm{CO} 2$ in the adsorption bed, the process is shifted to the second bed. The saturated bed is depressurized to ambient pressure. The efficiency of this process is up to $98 \%$. Continuous monitoring of a small-scale installation $(26 \mathrm{~m} 3 / \mathrm{h})$ in Sweden using pressure swing adsorption technique through carbon molecular sieves have given excellent results in terms of clean gas, energy efficiency and cost. Pandey and Fabian [11] used naturally occurring zeolite-Neopoliton Yellow Tuff (NYT) for adsorption. They found that the active component for $\mathrm{CO} 2$ adsorption is chabazite, which has adsorption capacity of $0.4 \mathrm{~kg} \mathrm{CO} 2$ per $\mathrm{kg}$ of chabazite at 1.50 bar and $228 \mathrm{C}$. During the adsorption process the $\mathrm{H} 2 \mathrm{~S}$ content is also reduced.

\section{Cryogenic Separation}

In a cryogenic method, crude biogas is compressed to approximately 80 bars. The compression is made in multiple stages with inter-cooling. The compressed gas is dried to avoid freezing during cooling process. The biogas is cooled with chillers and heat exchangers top $\mathrm{K} 458 \mathrm{C}$, condensed $\mathrm{CO} 2$ is removed in a separator. The $\mathrm{CO} 2$ is processed further to recover dissolved methane, which is recycled to the gas inlet. By this process more than $97 \%$ pure methane is obtained. No data is available on investment and operational cost. The basic flow diagram of Cryogenics Separations is shown in Fig.3.

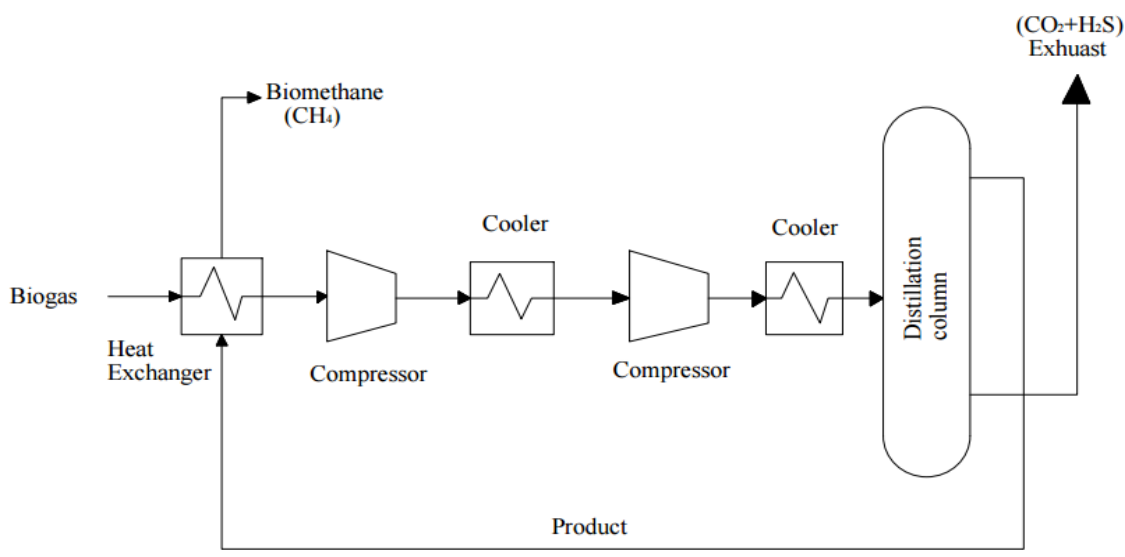

Fig. 3 Cryogenics Separations

\section{E. Chemical Conversion Method}

To attain extremely high purity in the product gas, chemical conversion method can be used. It reduces the undesirable gas concentrations to trace levels. Usually the chemical conversion process is used after bulk removal has been accomplished by other methods. One such chemical conversion process is methanation, in which $\mathrm{CO} 2$ and $\mathrm{H} 2$ are catalytically converted to methane and water. Chemical conversion process is extremely expensive and is not warranted in most biogas applications [12]. Due to highly exothermic nature of the methanation reactions, the removal of the heat from the methanator is a major concern in the process design. 
The requirement of the large amount of pure hydrogen also makes the process generally unsuitable. The basic flow diagram of Chemical Conversion is shown in fig.4.

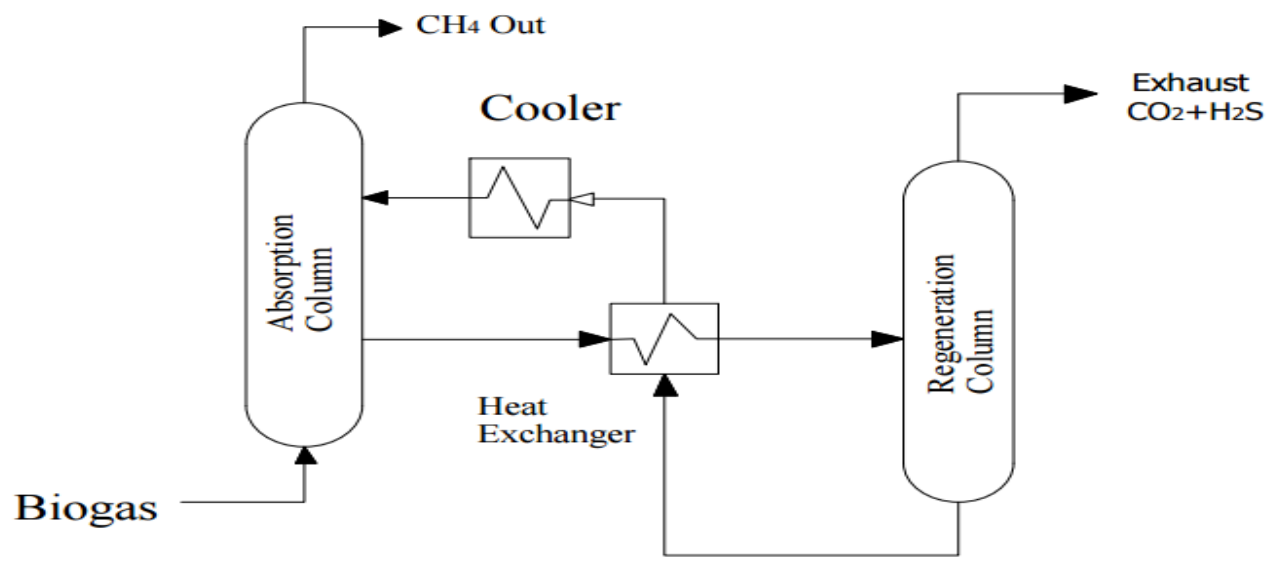

Fig.4 Chemical Conversion

\section{SCRUBBING OF $\mathrm{H}_{2} \mathrm{~S}$}

$\mathrm{H} 2 \mathrm{~S}$ is always present in biogas, although concentrations vary with the feedstock. It has to be removed in order to avoid corrosion in compressors, gas storage tanks and engines. $\mathrm{H} 2 \mathrm{~S}$ is poisonous and corrosive as well as environmentally hazardous since it is converted to sulphur dioxide by combustion. It also contaminates upgrading process. H2S can be removed either in the digester, from the crude biogas or in upgrading process [13]. The most commonly used H2S removal process can be classified into two general categories namely: (1) dry oxidation process and (2) liquid phase oxidation process [14].

\section{A. Dry oxidation process}

It can be used for removal of $\mathrm{H}_{2} \mathrm{~S}$ from gas streams by converting it either into sulphur or oxides of sulphur. This process is used where the sulphur content of gas is relatively low and high purities are required. Some of these methods are described below.

\section{1) Introduction of air/oxygen into the biogas system}

A small amount of oxygen (2-6\%) is introduced in the biogas system by using air pump. As a result, sulphide in the biogas is oxidized into sulphur and $\mathrm{H}_{2} \mathrm{~S}$ concentration is lowered.

$2 \mathrm{H}_{2} \mathrm{~S}+\mathrm{O}_{2}=2 \mathrm{~S}+2 \mathrm{H}_{2} \mathrm{O}$

This is a simple and low cost process. No special chemicals or equipment's are required. Depending on the temperature, the reaction time and place where the air is added, the $\mathrm{H}_{2} \mathrm{~S}$ concentration can be reduced by $95 \%$ to less than $50 \mathrm{ppm}$. However, care should be taken to avoid overdosing of air, as biogas in air is explosive in the range of $6-12 \%$, depending on the methane content [15].

\section{2) Adsorption using iron oxide}

$\mathrm{H}_{2} \mathrm{~S}$ reacts with iron hydro-oxides or oxides to form iron sulphide. The biogas is passed through iron oxide pellets, to remove $\mathrm{H}_{2} \mathrm{~S}$. When the pellets are completely covered with sulphur, these are removed from the tube for regeneration of sulphur. It is a simple method but during regeneration a lot of heat is released. Also the dust packing contains a toxic component and the method is sensitive to high water content of biogas. Wood chips covered with iron oxide have a somewhat larger surface to volume ratio than plain steel. Roughly $20 \mathrm{~g}$ of $\mathrm{H}_{2} \mathrm{~S}$ can be bound per $100 \mathrm{~g}$ of iron oxide chips. The application of wood chips is very popular particularly in USA. It is a low cost product, however, particular care has to be taken that the temperature does not rise too high while regenerating the iron filter [16]. $\mathrm{H}_{2} \mathrm{~S}$ can be adsorbed on activated carbon. The sulphur containing carbon can then either be replaced with fresh activated carbon or regenerated. It is a catalytic reaction and carbon acts as a catalyst [16].

\section{B. Liquid phase oxidation process}

This process is primarily used for the treatment of gases containing relatively low concentration of $\mathrm{H}_{2} \mathrm{~S}$. It may be either: (a) physical absorption process or (b) chemical absorption process. In physical absorption process the $\mathrm{H}_{2} \mathrm{~S}$ can be absorbed by the solvents. One of the solvent is water. But the consumption of water is very high for absorption of small amount of $\mathrm{H}_{2} \mathrm{~S}$. If some chemicals like $\mathrm{NaOH}$ are added to water, the absorption process is enhanced. It forms sodium sulphide or sodium hydrosulphide, which is not regenerated and poses problems of disposal. Chemical absorption of $\mathrm{H}_{2} \mathrm{~S}$ can take place with iron salt solutions like iron 
chloride. This method is extremely effective in reducing high $\mathrm{H}_{2} \mathrm{~S}$ levels. The process is based on the formation of insoluble precipitates. $\mathrm{FeCl}_{3}$ can be added directly to the digester slurry. In small anaerobic digester system, this process is most suitable. All other methods of $\mathrm{H}_{2} \mathrm{~S}$ removal are suitable and economically viable for largescale digesters. By this method the final removal of $\mathrm{H}_{2} \mathrm{~S}$ is about $10 \mathrm{ppm}$.

\section{BIOGAS COMPRESSION AND STORAGE}

Biogas, containing mainly methane, could not be stored easily, as it does not liquefy under pressure at ambient temperature (critical temperature and pressure required are $\mathrm{K} 82.58 \mathrm{C}$ and 47.5 bar, respectively). Compressing the biogas reduces the storage requirements, concentrates energy content and increases pressure to the level required overcoming resistance to gas flow. Compression is better in the scrubbed biogas. Integrated units with facilities for scrubbing, compressing and storing have been developed in certain developed countries. For instance a water scrubber coupled with a gas compressor is being promoted for uniform use in New Zealand. Similarly, the biogas produced from poultry manure is being dried, scrubbed, compressed and stored at a pressure of 4 bars in $0.2 \mathrm{~m}^{3}$ steel tanks in Belgium [17]. By purifying the biogas produced from the distillery wastes, scientists of Jadhavpur University, Kolkatta, India [18] claimed to have generated huge quantities of compressed methane, a gas with an immense potential and an alternative source of vehicle fuel. Experimenting with bulk distillery wastes, from alcohol manufacturing breweries, researchers produced the gas by biomethanation of the effluents. Similar results have also been reported from Netherlands, UK, Australia, New Zealand and USA. All these results indicate that biogas is one of the potential substitutes for present day fuels including CNG, petrol, diesel and LPG.Nema and Bhuchner [19] stressed on value addition to biogas by scrubbing and compressing, making it as good as the compressed natural gas (CNG). They reported the economic feasibility of producing energy from solid wastes of Delhi city. From 5000 tonnes wastes generated per day in Delhi, 100,000 $\mathrm{Nm}^{3} /$ day biogas can be produced which is equivalent to $309.5 \mathrm{~m}^{3}$ CNG worth US \$ 70,000 per day. Beside this, by adopting this technology 117 tonnes/day $\mathrm{CO}_{2}$ gas can be prevented from entering into the atmosphere. Khapre [4] conducted a study on scrubbing and compression of biogas and subsequently used it for domestic cooking. He found reduced requirement of scrubbed and compressed biogas $\left(0.353 \mathrm{~m}^{3}\right)$ than raw biogas $\left(0.591 \mathrm{~m}^{3}\right)$ for cooking a day's meal of a six member family. He stored the scrubbed and compressed biogas at a pressure of 7 bars in cylinder of $0.1 \mathrm{~m}^{3}$ capacity.

\section{CONCLUSIONS}

- The purpose of this study is simply people come to know which are absorbing techniques of pure methane gas from raw biogas. Presently, biogas is mainly used for cooking purpose in India.

- To tap full potential of biogas, need emerges for its commercialization by making it transportable. Therefore biogas scrubbing and compression at high pressure for storage in cylinders are essential.

- Different methods of scrubbing are reviewed and found that water scrubbing is simple, continuous and less expensive method for $\mathrm{CO}_{2}$ removal from biogas for Indian conditions.

- It simultaneously also removes $\mathrm{H}_{2} \mathrm{~S}$. After removal of $\mathrm{CO}_{2}$, biogas is enriched in methane and becomes equivalent to natural gas.

- It can be used for all such applications for which natural gas is being used viz. as a fuel for vehicles, CHP, electricity generation, etc.

\section{REFERENCES}

[1] Biogas upgrading and utilization,IEA Bioenergy Task 24 - Energy from biological conversion of organic waste Lindberg, Wellinger; Sweden \& Switzerland, 2006. www.iea-biogas.net

[2] Techniques for transformation of biogas to biomethane,,Biomass and Bioenergy,35,2011,1633-1645 Ryckebosch, Drouillon,Vervaeren;2011 www.journals.elsevier.com/biomass-and-bioenergy

[3] Dubey AK. Wet scrubbing of carbon dioxide, Annual report of CIAE, Bhopal (India); 2000.

[4] Khapre UL. Studies on biogas utilization for domestic cooking. Paper presented at XXV annual convention of ISAE, held at CTAE, Udaipur; 1989.

[5] Bhattacharya TK, Mishra TN, Singh B. Techniques for removal of CO2 and H2S from biogas, Paper presented at XXIV annual convention of ISAE, held at PKV, Akola, 1988.

[6] Vijay VK., Studies on utilization of biogas for improved performance of duel fuel engine, ME (Ag.) Thesis, CTAE, Udaipur; 1989.

[7] Shannon R Biogas conference proceedings2000 http://www.rosneath.com.all/ipc6/ch08/shannon2/.

[8] Patel H. The biogas alternatives. IREDA News 2001; 12(3):93-6.

[9] Biswas TD, Kartha ARS, Pundarikakhadu R. Removal of carbon dioxide from biogas. Proceedings of national symposium on biogas technology and uses. New Delhi: IARI; 1977.

[10] Schomaker IT, Boerboom AHHM, Vissel A, Pfeifer AE, Technical summary on gas treatment. Anaerobic digestion of agro industrial wastes: information network project FAIR-CT96-2083; 2000. 
[11] Pandey DR, Fabian C, Feasibility studies on the use of naturally accruing molecular sieves for methane enrichment from biogas. Gas Separation and Purification ,1989; 3:143-7.

[12] Glub JC, Diaz LF, Biogas purification process. Biogas and alcohol fuels production, vol II.: The JP Press Inc; 1991.

[13] Hagen M, Polman E. Adding gas from biomass to the gas grid. Final report submitted to Danish Gas Agency; 2001:26-47.

[14] Wise DL, Analysis of systems for purification of fuel gas. Fuel gas production from biomass, vol 2. Boca Raton, FL: CRC Press; 1981.

[15] Wellinger A, Lindeberg A,Biogas upgrading and utilization..Task 24: energy from biological conversion of organic wastes 1999, 1-19.

[16] Hagen M, Polman ,. Adding gas from biomass to the gas grid.,Final report submitted to Danish Gas Agency; 2001:26-47.

[17] Anonymous. Biogas technology: an information package. Mumbai: TERI; 1985.

[18] Mande S. Scientist generates vehicle fuel from distillery waste, a news brief. SESI Newslett 2000; 22(4):5.

[19] Nema A, Bhuchner K. Kampogas,a robust technology for solid waste to energy projects.,Bio-EnergyNews 2002; $6(2), 10-12$ 